\title{
In vitro growth and content of vincristine and vinblastine of Catharanthus roseus $L$. hairy roots in response to precursors and elicitors
}

\author{
Phuong Thi Bach Vu ${ }^{1,2^{\star \star}}$, Dai Minh Cao ${ }^{1,2^{\star \star}}$, Anh Lan Bui ${ }^{1,2}$, Nhut Nhu Nguyen ${ }^{1,2}$, Le Van Bui ${ }^{1,2}$ \& Phuong Ngo Diem \\ Quach ${ }^{1,2^{\star}}$
}

${ }^{1}$ Laboratory of Plant Biotechnology, Department of Plant Biotechnology and Biotransformation, University of Sciences, Ho Chi Minh City 7000 , Vietnam

${ }^{2}$ Vietnam National University, Ho Chi Minh City 7000, Vietnam

*Email:qndphuong@hcmus.edu.vn

${ }^{\star *}$ Co-first Author

OPEN ACCESS

\section{ARTICLE HISTORY}

Received: 16 June 2021

Accepted: 28 November 2021

Available online

Version 1.0:01 January 2022

\section{Check for updates}

\section{Additional information}

Peer review: Publisher thanks Sectional Editor and the other anonymous reviewers for their contribution to the peer review of this work.

Reprints \& permissions information is available at https://horizonepublishing.com/ journals/index.php/PST/open_access_policy

Publisher's Note: Horizon e-Publishing Group remains neutral with regard to jurisdictional claims in published maps and institutional affiliations.

Indexing: Plant Science Today, published by Horizon e-Publishing Group, is covered by Scopus, Web of Science, BIOSIS Previews, Clarivate Analytics, etc. See https:// horizonepublishing.com/journals/index.php/ PST/indexing_abstracting

Copyright: @ $\odot$ The Author(s). This is an openaccess article distributed under the terms of the Creative Commons Attribution License, which permits unrestricted use, distribution and reproduction in any medium, provided the original author and source are credited (https://creativecommons.org/licenses/ by/4.0/)

\section{CITE THIS ARTICLE}

Vu PT B, Cao D M, Bui A L, Nguyen N N, Bui L $V$, Quach P N D. In vitro growth and content of vincristine and vinblastine of Catharanthus roseus $\mathrm{L}$. hairy roots in response to precursors and elicitors. Plant Science Today. 2022;9 (1):21-28. https://doi.org/10.14719/pst.1337

\begin{abstract}
Catharanthus roseus $\mathrm{L}$. is a medicinal plant that produces numerous indole terpenoid alkaloids, including vincristine and vinblastine, which are used for cancer treatment. The effect of specified precursors (L-phenylalanine, Ltyrosine) and elicitors (chitosan, methyl jasmonate) on C. roseus hairy roots (CHR) growth has been examined in order to increase the content of vincristine and vinblastine. Our results showed that CHR generated by an Agrobacterium rhizogenes strain isolated in Vietnam was capable of producing both vincristine and vinblastine when subjected to precursors, but only vinblastine when exposed to elicitors. However, both precursors and elicitors were evaluated to have an effect on increasing the accumulation of TIAs in CHR. In particular, the use of elicitors required more time to find the appropriate induction conditions, while the use of precursors gave outstanding efficiency in the treatment with $1 \mu \mathrm{M}$ phenylalanine. The greatest yields of vincristine $\left(51.99 \mathrm{\mu g} \mathrm{g}^{-1} \mathrm{DW}\right)$ and vinblastine $\left(699.92 \mathrm{\mu g} \mathrm{g}^{-1} \mathrm{DW}\right)$ were obtained in the $7^{\text {th }}$ week (with $0.306 \mathrm{~g}$ DW biomass). This result is the first time we might boost the levels of vincristine and vinblastine in our CHR clone generated by the Vietnam strain of $A$. rhizogenes.
\end{abstract}

\section{Keywords \\ Catharanthus roseus, elicitors, hairy root, precursors, vinblastine, vincristine.}

\section{Introduction}

Catharanthus roseus L. is a tropical perennial medicinal plant in the family Apocynaceae. C. roseus, native and also endemic to Madagascar, is a herb, 30-100 cm tall. It grows wild in the tropical and subtropical areas of the world and is widely cultivated (1). There are two common cultivars of $C$. roseus named based on their flower color that is the pink-flowered 'Rosea' and the white-flowered 'Alba' $(1,2)$. C. roseus is propagated by seeds or cuttings (3). The flowers bloom year-round and are white to dark pink with a dark red center, with a base tube about $2.5-3 \mathrm{~cm}$ and a corolla about $2-5 \mathrm{~cm}$ diameter with five-lobed petals (4). The flowers of the wild plant are naturally pale pink with purple in the center, but gardeners have developed varieties (more than 100) with colors ranging from white, pink to purple (3).

Catharanthus roseus is used as a folk remedy in many countries around the world and has been time-tested and validated by people's beliefs (2). C. roseus is used in the treatment of many diseases such as diabetes, blood pressure, asthma, constipation, cancer, menorrhagia, rheumatism, indigestion, skin diseases, bloody diarrhea and depression $(3,4)$. All parts of $C$. roseus, including roots, leaves, flowers and stems are used as 
herbal medicine. Because of its therapeutic usefulness, it has attracted a lot of attention from scientific researchers. Published studies show that $C$. roseus is a medicinal plant with many pharmacological effects such as antimicrobial, antioxidant, anthelmintic, antifeedant, antisterility, antidiarrheal, antidiabetic (1). Therefore, the research on $C$. roseus will be further invested in to exploit the more herbal value of this plant.

Catharanthus roseus has received much pharmaceutical attention because of its chemical composition, which contains more than 130 different indole terpenoid alkaloids (TIAs), some of which are pharmacologically important and potent, such as vinblastine and vincristine. These were demonstrated with the high effectiveness of antioxidant, hypertension, diabetes and cancer treatments $(5,6)$. Vinblastine and vincristine are two popular $C$. roseus TIAs regarded as the first natural drugs used in the prevention and cure of malignant tumor diseases (7). Both vincristine and vinblastine are very expensive because the accumulated concentrations from the whole plant are very low (approximately $0.0005 \% \mathrm{w} / \mathrm{w}$ ) (6), it is estimated that $500 \mathrm{~kg}$ of dried $C$. roseus leaves produces only $1 \mathrm{~g}$ of vinblastine, this makes the extraction of $C$. roseus very expensive. Low levels of vincristine and vinblastine are mostly connected with the geographical separation of biosynthetic sites in the plant. It mostly refers to the TIAs biosynthesis pathway of great degree specialization in leaf cells (8). Because of the poor recovery of vinblastine and vincristine from the costly extraction approach, scientists are particularly interested in increasing their production using various biological strategies.

Biotechnology has succeeded in producing many species of medicinal plants with high activity by in vitro culture. The most promising biotechnological tool for high production of these compounds is hairy root culture (9). Hairy root is formed by a mediate interaction between soil bacterium Agrobacterium rhizogenes and plant. This transformation process has delivered a precious by-product, "hairy root" that can develop unlimitedly in culture media (10). Hairy root might regard as plant factory that generated similar secondary metabolites and even higher than parents in a short period of time (10). Hairy root culture may completely expand to industrial scale due to independent growth in liquid medium without exogenous hormones, stable genetic and biochemical expression.

In order to enhance content and reduce harvest time of valuable secondary metabolites in hairy root, precursors and elicitors have been proposed as promising strategies (11). Many previous studies have demonstrated that precursors (phenylalanine, tyrosine) and elicitors (methyl jasmonate, chitosan, fungal elicitation) may accelerate the TIAs contents in CHR such as ajmalicine, serpentine, ajmalicine, catharanthine, tabersonine and lochnericine (12-14). Furthermore, vinblastine and vincristine accelerations were less studied, maybe because these compounds located in almost final positions of TIAs biosynthesis pathways (5).
In the current work, the effects of precursors (types and concentrations) and elicitors (types, dosages, and time exposure) on CHR growth and alkaloids (vinblastine and vincristine) accumulation were evaluated.

\section{Materials and Methods}

\section{Agrobacterium rhizogenes preparation}

Agrobacterium rhizogenes $\mathrm{C} 18$ strain was isolated in the Laboratory of Plant Biotechnology, Faculty of Biology Biotechnology, Ho Chi Minh University of Sciences, Vietnam National University (15). A. rhizogenes C18 strain was cultured and stored on Yeast Mannitol Broth (YMB) agar for $48 \mathrm{hrs}$ at $25^{\circ} \mathrm{C}$ and shaken at $180 \mathrm{rpm}$. Bacterial broth after culture with an $\mathrm{OD}_{600} \mathrm{~nm}$ of about 1.7-1.8 was diluted to an $\mathrm{OD}_{600} \mathrm{~nm} 1.0$ to be used as a source of bacteria for infection.

\section{CHR preparation}

$\mathrm{CHR}$ was induced by $A$. rhizogenes $\mathrm{C} 18$ according to the procedure of Nhut et al. (16).

\section{Preparation of seedlings in vitro}

Catharanthus roseus VIN077 seeds were provided by Vietnam Flower Seed Company FVN (Ho Chi Minh City). Seeds were washed with diluted soapy water for $10 \mathrm{~min}$ and then rinsed with clean water. Next, the seeds were washed with $80 \%$ ethanol for $1 \mathrm{~min}$ and soaked in $5 \%$ $\mathrm{NaOCl}$ solution for $15 \mathrm{~min}$, and then the seeds were washed with sterile distilled water. Seeds after sterilization were placed on $1 / 2 \mathrm{MS}$ medium (Murashige \& Skoog) supplemented with $3 \%(\mathrm{w} / \mathrm{v})$ sucrose and $0.8 \%(\mathrm{w} / \mathrm{v})$ phytoagar $\left(\mathrm{pH} \mathrm{5.8)}\right.$ at $25^{\circ} \mathrm{C}$ with dark conditions. After 5 days, transfer the seedlings to 1500 lux white light (16 hrs/day). After 8 weeks of culture, the plants are about $5-7 \mathrm{~cm}$ tall and have 4-5 pairs of developed true leaves that will be used as infectious materials to induce hairy roots.

\section{The procedure for hairy root induction}

The true leaves in vitro were wound in the main veins of the leaves. Then, the sample was soaked in A. rhizogenes suspension for $5 \mathrm{~min}$. Next, the samples were co-cultured on $1 / 2 \mathrm{MS}$ medium in the dark for 7 days at $25^{\circ} \mathrm{C}$. Remove A. rhizogenes by transferring samples to $1 / 2 \mathrm{MS}$ medium supplemented with cefotaxime $500 \mathrm{mg} \mathrm{L}^{-1}$ and cultured in the dark for 7 days at $25{ }^{\circ} \mathrm{C}$. After that, the samples were transferred to $1 / 2 \mathrm{MS}$ medium and continued to grow in the dark at $25{ }^{\circ} \mathrm{C}$. Hairy roots are formed after 2-3 weeks of infection.

\section{Hairy roots culture in liquid medium}

CHR was cultured in liquid $1 / 2$ B5 medium (Gamborg's B5) (17) containing sucrose $2 \%(\mathrm{w} / \mathrm{v}), \mathrm{pH}=5.7 \pm 0.1$. The initial culture density was $0.2 \mathrm{~g}$ fresh weight with $50 \mathrm{ml}$ liquid medium in a $250 \mathrm{ml}$ erlen, shaken in an $80 \mathrm{rpm}$ rotary shaker at $25{ }^{\circ} \mathrm{C}$ in a fully dark setting. Precursors and elicitors will be added to the culture medium to investigate the growth and content of vincristine and vinblastine of hairy roots. The control treatment was hairy roots grown in the medium without adding precursors and elicitors. 


\section{Investigating the effect of precursors}

L-phenylalanine (HiMedia, India) and L-tyrosine (Merk, Germany) were provided at the beginning with different concentrations: $0,1,10$ and $100 \mu \mathrm{M}$. CHR dry weight (DW) and contents of vincristine and vinblastine were measured every week for 8 weeks.

\section{Investigating the effect of elicitors}

In the late exponential phase of culture (6th week): chitosan (from shrimp shells, $>=75 \%$ (deacetylated), China): 0, 50, 100 and $150 \mathrm{mg} \mathrm{L}^{-1}$ and methyl jasmonate (Sigma, American): 0, 50, 100 and $150 \mu \mathrm{M}$ were added to the culture media. The exposure times for each elicitor dosages were 2, 4 and 6 days. CHR dry weight (DW) and contents of vincristine and vinblastine were measured after 2, 4 and 6 treated days.

Analysis of vincristine and vinblastine contents by HPLC method

For vincristine and vinblastine ( $\mu \mathrm{g} / \mathrm{g} D \mathrm{DW})$ measurement, 0.5 $\mathrm{g}$ dried CHR was extracted from harvested samples and then evaluated by HPLC using a previously published method (18). HPLC analysis used a chromatographic system consisting of a G1312 BinPump, a 7725-type injector valve with a $20 \mu$ loop, a G1314A variable wavelength probe, a PT100 column oven, and an Agilent ChemStation. Reversed phase column $(150 \mathrm{~mm} \times 4.6 \mathrm{~mm} ; 5 \mu \mathrm{m})$ operated at $25^{\circ} \mathrm{C}$ and eluted with $0.1 \%$ triethylamine $(A)$ and methanol (B) according to the following procedure: $0-40 \mathrm{~min}$, linear gradient from 50:50 (A: B) to 30:70; 40-50 min, elution class with 10:90; and 50-60 min, elution class with 50:50 to equilibrate the column. All chromatographic experiments had a flow rate of $0.8 \mathrm{ml} / \mathrm{min}$, an injection volume of $10 \mu \mathrm{l}$ and the effluent was monitored at $280 \mathrm{~nm}$ (18).

\section{Statistical analysis}

All experiments in this study were repeated 3 times and each treatment in these experiments was repeated 10 times with the follow-up parameters being dry weight ( $\mathrm{g} D \mathrm{D}$ ) and

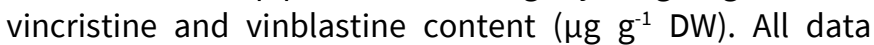
were analyzed using the SPSS 16.0 (Copyright SPSS Inc.). Experimental results were represented as mean \pm standard deviation (SD). Differences between means were evaluated by Duncan's multiple range tests. Statistical significance was accepted at a level of $p<0.05$.

\section{Results and Discussion}

\section{The effect of precursors}

Fig. 1 and 2, Table 1 and 2 show that phenylalanine and tyrosine introduction increased both vincristine and vinblastine accumulation, whereas the control sample was noted in traces.

\section{Effects of L-phenylalanine}

The DW, VBL, and VCR were evaluated after adding various PHE concentrations during 8 weeks of culture.

As shown in Fig. 1B, by feeding 0, 1, and $10 \mu \mathrm{M}$ PHE, the lag phase of $\mathrm{CHR}$ (1 week) was shortened in comparison with the $100 \mu \mathrm{M}$ PHE addition (2 weeks). At week 4 of cul-

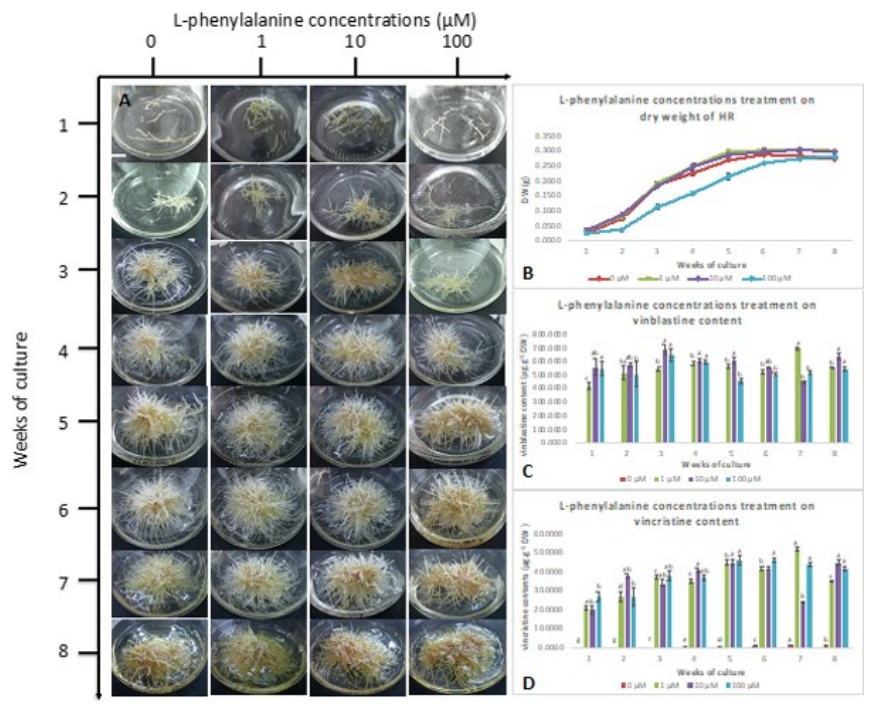

Fig. 1. Effect of various L-phenylalanine concentrations on CHR. (A) CHR phenotypes, (B) dry weight, (C) vinblastine contents and (D) vincristine contents. Error bars represent standard deviations. The value in line marked with different lower-case letters denote significant differences between samples at $\mathrm{p}<0.05$ (Duncan's multiple range test). Scale bar $=1 \mathrm{~cm}$.

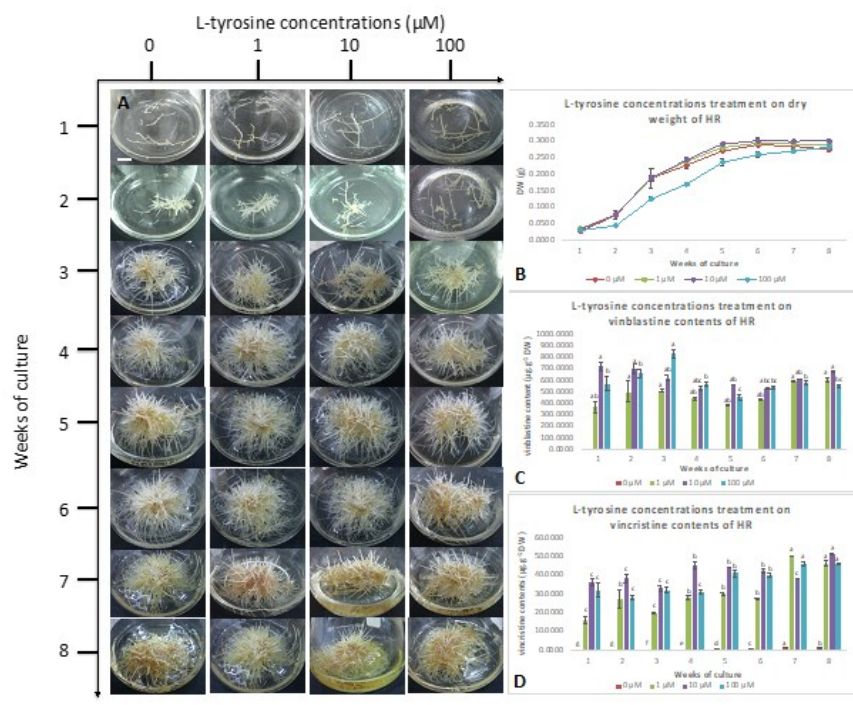

Fig. 2. Effect of various L-tyrosine concentrations on CHR. (A) CHR phenotypes, (B) dry weight, (C) vinblastine contents and (D) vincristine contents. Error bars represent standard deviations. The value in line marked with different lower-case letters denote significant differences between samples at $p<$ 0.05 (Duncan's multiple range test). Scale bar $=1 \mathrm{~cm}$.

ture, the presence of 1 and $10 \mu \mathrm{M}$ PHE could enhance the growth of CHR comparable with the root control. By only adding $1 \mu \mathrm{M}$ PHE, the CHR may develop its growth similar to the $10 \mu \mathrm{M}$ feeding. The growth curve may be clearly divided into [1] the lag (1 - 2 weeks), [2] the exponential (2 - 5 weeks), and [3] the stationary (5 - 8 weeks) growth stage. The CHR accelerated and reached a peak of DW at week $5^{\text {th }}$ $(0.2987 \mathrm{~g})$.

Regarding TIA contents (Fig. 1C), there were various distributions of VBL and VCR contents in different dosages of PHE addition. The VBL did not observe in the $\mathrm{CHR}$ control but strongly accumulated when using precursor. By feeding 10 and $100 \mu \mathrm{M}$ PHE, CHRs early achieved their highest VBL contents in week $3^{\text {rd }}\left(690.00 \mu \mathrm{g} \mathrm{g}^{-1} \mathrm{DW}\right)$ and $1^{\text {st }}\left(550.00 \mu \mathrm{g} \mathrm{g}^{-1}\right.$ DW) respectively. However, their VBL contents remained or even reduced gradually in further weeks. The addition of 1 $\mu \mathrm{M}$ PHE could reveal an outstanding effect, CHR achieved the highest VBL content at week $7^{\text {th }}\left(699.92 \mu \mathrm{g} \mathrm{g} \mathrm{g}^{-1} \mathrm{DW}\right) . \mathrm{A}$ 
Table 1. Effect of various L-phenylalanine concentrations on CHR

\begin{tabular}{|c|c|c|c|c|c|c|c|c|c|}
\hline \multicolumn{2}{|c|}{ Week of culture } & 1 & 2 & 3 & 4 & 5 & 6 & 7 & 8 \\
\hline \multirow{4}{*}{ DW (g) } & $0 \mu \mathrm{M}$ & $0.0266^{f}$ & $0.0746^{e}$ & $0.1870^{d}$ & $0.2268^{c}$ & $0.2699^{b}$ & $0.2879^{a}$ & $0.2844^{a}$ & $0.2732^{\mathrm{a}}$ \\
\hline & $1 \mu \mathrm{M}$ & $0.0367^{e}$ & $0.0824^{d}$ & $0.1927^{c}$ & $0.2491^{b}$ & $0.2987^{a}$ & $0.3024^{\mathrm{a}}$ & $0.3064^{\mathrm{a}}$ & $0.3006^{a}$ \\
\hline & $10 \mu \mathrm{M}$ & $0.0366^{e}$ & $0.0884^{d}$ & $0.1841^{c}$ & $0.2481^{b}$ & $0.2877^{\mathrm{a}}$ & $0.2986^{a}$ & $0.3039^{a}$ & $0.2977^{\mathrm{a}}$ \\
\hline & $100 \mu \mathrm{M}$ & $0.0254^{e}$ & $0.0387^{e}$ & $0.1133^{d}$ & $0.1605^{c}$ & $0.2153^{b}$ & $0.2600^{\mathrm{ab}}$ & $0.2737^{a}$ & $0.2818^{\mathrm{a}}$ \\
\hline \multirow{4}{*}{$\begin{array}{c}\text { VBL } \\
\left(\mu \mathrm{g} \mathrm{g}^{-1} \mathrm{DW}\right)\end{array}$} & $0 \mu \mathrm{M}$ & 0.0000 & 0.0000 & 0.0000 & 0.0000 & 0.0000 & 0.0000 & 0.0000 & 0.0000 \\
\hline & $1 \mu \mathrm{M}$ & $419.6185^{c}$ & $520.2104^{b c}$ & $549.9049^{b}$ & $589.9210^{\mathrm{b}}$ & $569.9364^{\mathrm{b}}$ & $530.0000^{\mathrm{b}}$ & $699.9238^{a}$ & $560.0000^{b}$ \\
\hline & $10 \mu \mathrm{M}$ & $560.0000^{\mathrm{ab}}$ & $580.0000^{\mathrm{ab}}$ & $690.0000^{\mathrm{a}}$ & $610.0819^{a}$ & $610.0000^{\mathrm{a}}$ & $559.9375^{\mathrm{ab}}$ & $449.9507^{\mathrm{b}}$ & $639.9283^{a}$ \\
\hline & $100 \mu \mathrm{M}$ & $550.0000^{\mathrm{a}}$ & $510.4393^{b}$ & $650.1912^{\mathrm{a}}$ & $599.8754^{a}$ & $459.9288^{b}$ & $510.0654^{b}$ & $520.0000^{\mathrm{b}}$ & $550.0000^{\mathrm{a}}$ \\
\hline \multirow{3}{*}{$\begin{array}{c}\text { VCR } \\
\left(\mu \mathrm{g} \mathrm{g}^{-1} \mathrm{DW}\right)\end{array}$} & $0 \mu \mathrm{M}$ & $0.0500^{\mathrm{g}}$ & $0.0800^{\mathrm{g}}$ & $0.1200^{f}$ & $0.3700 \mathrm{e}$ & $0.7000^{d}$ & $1.1101^{\mathrm{c}}$ & $1.6302^{\mathrm{a}}$ & $1.3300^{\mathrm{b}}$ \\
\hline & $1 \mu \mathrm{M}$ & $20.9809^{e}$ & $27.0109^{d}$ & $36.9936^{c}$ & $34.9953^{c}$ & $44.9950^{b}$ & $42.0000^{b}$ & $51.9943^{\mathrm{a}}$ & $35.0000^{c}$ \\
\hline & $10 \mu \mathrm{M}$ & $20.0000^{b}$ & $38.0000^{\mathrm{ab}}$ & $34.0000^{\mathrm{ab}}$ & $41.0055^{\mathrm{a}}$ & $45.0000^{\mathrm{a}}$ & $41.9953^{\mathrm{a}}$ & $23.9974^{b}$ & $44.9950^{\mathrm{a}}$ \\
\hline
\end{tabular}

The value marked with different lower-case letters denote significant differences between samples at $p<0.05$ (Duncan's multiple range test)

Table 2. Effect of various L-tyrosine concentrations on CHR

\begin{tabular}{|c|c|c|c|c|c|c|c|c|c|}
\hline \multicolumn{2}{|c|}{ Week of culture } & \multirow{2}{*}{$\frac{1}{0.0266^{f}}$} & \multirow{2}{*}{$\begin{array}{c}2 \\
0.0746^{\mathrm{e}}\end{array}$} & \multirow{2}{*}{$\frac{3}{0.1870^{d}}$} & \multirow{2}{*}{$\begin{array}{c}4 \\
0.2268^{c}\end{array}$} & \multirow{2}{*}{$\begin{array}{c}5 \\
0.2699^{b}\end{array}$} & \multirow{2}{*}{$\begin{array}{c}6 \\
0.2879^{a}\end{array}$} & \multirow{2}{*}{$\begin{array}{c}7 \\
0.2844^{a}\end{array}$} & \multirow{2}{*}{$\begin{array}{c}8 \\
0.2732^{\mathrm{a}}\end{array}$} \\
\hline & $0 \mu \mathrm{M}$ & & & & & & & & \\
\hline \multirow{3}{*}{$\mathrm{DW}(\mathrm{g})$} & $1 \mu \mathrm{M}$ & $0.0356^{e}$ & $0.0760^{d}$ & $0.1880^{c}$ & $0.2388^{b}$ & $0.2800^{\mathrm{a}}$ & $0.2934^{a}$ & $0.2913^{a}$ & $0.2900^{\mathrm{a}}$ \\
\hline & $10 \mu \mathrm{M}$ & $0.0318^{e}$ & $0.0770^{d}$ & $0.1890^{c}$ & $0.2429^{b}$ & $0.2913^{\mathrm{a}}$ & $0.3005^{\mathrm{a}}$ & $0.2992^{\mathrm{a}}$ & $0.3006^{\mathrm{a}}$ \\
\hline & $100 \mu \mathrm{M}$ & $0.0298^{e}$ & $0.0436^{e}$ & $0.1252^{d}$ & $0.1697^{c}$ & $0.2360^{b}$ & $0.2590^{\mathrm{a}}$ & $0.2692^{\mathrm{a}}$ & $0.2820^{\mathrm{a}}$ \\
\hline \multirow{4}{*}{$\begin{array}{l}\text { VBL } \\
\left(\mu g g^{-1}\right. \\
D W)\end{array}$} & $1 \mu \mathrm{M}$ & $370.0000^{\mathrm{ab}}$ & $499.7810^{\mathrm{a}}$ & $509.9096^{a}$ & $440.0000^{\mathrm{ab}}$ & $380.0452^{\mathrm{ab}}$ & $430.0000^{\mathrm{ab}}$ & $589.9325^{\mathrm{a}}$ & $600.0000^{a}$ \\
\hline & $10 \mu \mathrm{M}$ & $720.7547^{\mathrm{a}}$ & $700.3641^{\mathrm{a}}$ & $619.8906^{\mathrm{ab}}$ & $530.0000^{\mathrm{abc}}$ & $560.0000^{\mathrm{ab}}$ & $529.9412^{\mathrm{abc}}$ & $610.0680^{\mathrm{ab}}$ & $680.0000^{\mathrm{a}}$ \\
\hline & $100 \mu \mathrm{M}$ & $570.0000^{\mathrm{b}}$ & $659.4954^{b}$ & $830.0000^{a}$ & $570.1120^{b}$ & $450.0000^{c}$ & $540.0000^{\mathrm{bc}}$ & $580.0000^{b}$ & $550.0650^{\mathrm{bc}}$ \\
\hline & $0 \mu \mathrm{M}$ & $0.0500^{\mathrm{g}}$ & $0.0800^{\mathrm{g}}$ & $0.1200^{f}$ & $0.3700^{\mathrm{e}}$ & $0.7000^{d}$ & $1.1101^{c}$ & $1.6302^{\mathrm{a}}$ & $1.3300^{\mathrm{b}}$ \\
\hline \multirow{2}{*}{$\begin{array}{l}\text { VCR } \\
\left(\mu \mathrm{g} \mathrm{g}^{-1}\right. \\
\mathrm{DW})\end{array}$} & $10 \mu \mathrm{M}$ & $36.0377^{c}$ & $38.0198^{c}$ & $32.9942^{c}$ & $45.0000^{\mathrm{b}}$ & $44.0000^{b}$ & $41.9953^{b}$ & $38.0042^{c}$ & $51.0000^{\mathrm{a}}$ \\
\hline & $100 \mu \mathrm{M}$ & $32.0000^{c}$ & $27.9786^{c}$ & $32.0000^{c}$ & $31.0061^{c}$ & $41.0000^{b}$ & $40.0000^{\mathrm{b}}$ & $46.0000^{\mathrm{a}}$ & $46.0054^{a}$ \\
\hline
\end{tabular}

The value marked with different lower-case letters denote significant differences between samples at $p<0.05$ (Duncan's multiple range test).

description of VCR contents by adding different PA concen- PHE and the control was given in Fig. 6A and 6B respectivetrations was revealed in Fig. 1D. The VCR was presented in ly.

all cultures but was remarkably increased when only add-

ing PHE. In 1, 10 and $100 \mu \mathrm{M}$ PHE, CHR accumulated the greatest VCR contents at week $7^{\text {th }}\left(51.99 \mu \mathrm{g} \mathrm{g} \mathrm{g}^{-1} \mathrm{DW}\right), 4^{\text {th }}$

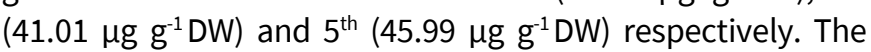
HPLC analysis of VCR accumulated in CHR cultured in $1 \mu \mathrm{M}$

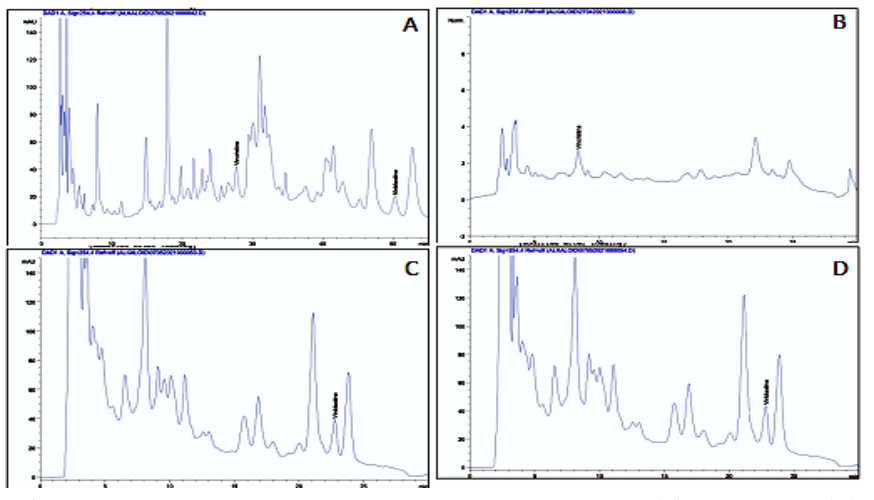

Fig. 6. HPLC analysis of the CHR extract with addition of (A) $1 \mu \mathrm{M}$ PHEL, (B) the control hairy root after 7 weeks of culture, (C) $150 \mathrm{mg} \mathrm{L}^{-1}$ chitosan after 6 days of elicitation, (D) $50 \mu \mathrm{M}$ methyljasmonate after 2 days of elicitation.

\section{Effects of L-tyrosine}

CHR was cultured in liquid medium contained numerous TYR concentrations. The DW, VBL and VCR were evaluated periodically in a duration of eight weeks.

The effect of TYR concentrations on DW was described in Fig. 2B. When adding 0, 1 and $10 \mu \mathrm{M}$ TYR, the lag phase of CHR (1 week) was shortened in comparison with the $100 \mu \mathrm{M}$ PHE addition (2 weeks). At week 5 of culture, the appearance of 1 and $10 \mu \mathrm{M}$ TYR could elevate the growth of CHR comparable with the root control. Furthermore, with only providing $1 \mathrm{mM}$ TYR, the CHR may generate growth similar to that of a $10 \mathrm{mM}$ feeding. The growth curve can be clearly divided into three stages: [1] the lag ( $1-2$ weeks), [2] the exponential (2 - 5 weeks), and [3] the stationary (5 8 weeks) growth stage. The CHR developed and then achieved a peak of DW at week $5^{\text {th }}(0.2800 \mathrm{~g})$.

The effects of different dosages of TYR on VBL and VCR contents were revealed in Fig. $1 C$ and 1D. The VBL in CHR has just started to accumulate when only feeding TYR 
into cultural medium. In the treatment of TYR, the VBL ered that PHEL is more appropriate than TYR for TIA biosynachieved the greatest content quite early in lag phase (from thesis pathway. For the increase of TIA content in CHR, the $1^{\text {st }}$ to $3^{\text {rd }}$ week) and then nearly maintained during 8 there were several studies using terpenoid precursor such weeks. The significant production of VCR happened in the as loganin that could enhance the catharanthine by $26 \%$, temporary growth stage. The additions of 1,100 (in the $7^{\text {th }}$ ajmalicine by $84 \%$, lochnericine by $119 \%$ and tabersonine week) and $10 \mu \mathrm{M}$ (in the $8^{\text {th }}$ week) reached the highest con- by $225 \%$ in the induced samples (23). A study, it was reporttent: $49.99,46.00$ and $51.00 \mathrm{\mu g} \mathrm{g}^{-1} \mathrm{DW}$ respectively.

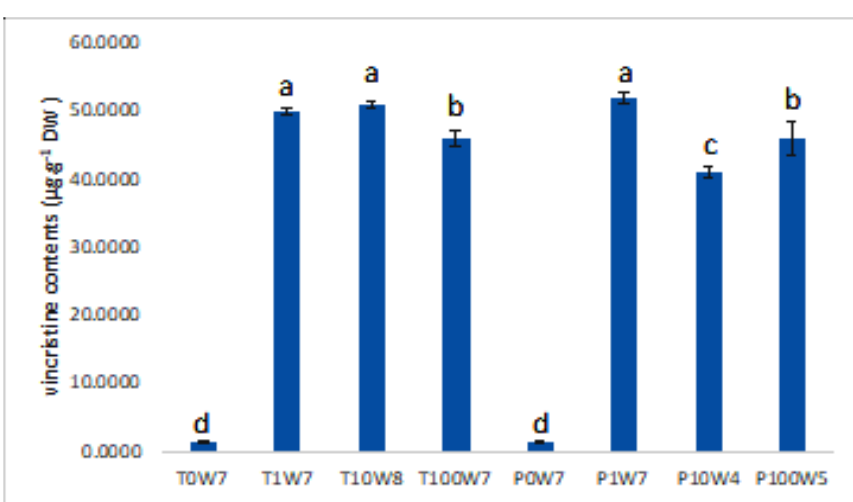

Fig. 3. The VCR (B) contents among the most effective PA and TYR concentrations. Error bars represent standard deviations. The value in line marked with different lower-case letters denote significant differences between samples at $p<0.05$ (Duncan's multiple range test). ( $T$ : tyrosine concentration, $\mathrm{P}$ : phenylalanine concentration, W: week).

A comparison between PHEL and TYR concentrations affected on VCR content was illustrated in Fig. 3. The VCR content parameter was priority chosen due to its economic value. Although VBL and VCR could help to specifically treat many cancer diseases. The cost for using VCR ( $\$$ 15 million $/ \mathrm{kg}$ ) is much more than VBL (\$2 million/kg). The T1W7, T10W8 and P1W7 had created a remarkable effect on increasing VCR content. The VBL contents accumulated in them were then compared. As a result, the T10W8 and P1W7 could produce significantly higher amounts of VBL than the T1W7. Regarding economic efficiency, P1W7 is not only using less precursor dosage but also shortening the harvest time in comparison with T10W8. Therefore, in this study, using $0.1 \mu \mathrm{M}$ PHEL may consider as a reasonable strategy for effectively obtaining VBL and VCR in our CHR culture.

At the appropriate concentration, both PHEL and TYR could increase the growth of CHR in comparison with the control. This root growth encouragement may be due to the extra supply of nitrogen nutrients as amino acids characteristics of PHEL and TYR However, precursors at high concentrations may hamper the absorbent of other nutrients lead to reduce biomass production .

There was a noted observation of the VBL and VCR contents. While the VBL often accumulated in early stage of culture (week 1 - week 3), the VCR presented in later phase (week 7 - week 8 ). This issue could be explained by understanding the TIA biosynthesis pathway. Firstly, vinblastine (a dimeric indole alkaloid) was made by coupling vindoline and catharanthine under catalysis of horseradish peroxidase (21). Afterwards, vinblastine is then converted into vincristine by the oxidation of its methyl group

However, the interesting discovery was by adding 1 $\mu \mathrm{M}$ PHEL, the CHR could produce both the greatest VBL and VCR contents after 7 weeks of culture. It could be consided that with loganin feeding, ajmalicine content $(3.27 \mathrm{mg} \mathrm{L}$ $\left.{ }^{1}\right)$ was improved by 2.3 -fold and there was 1.8 -fold increase in the yield of serpentine $\left(2.51 \mathrm{mg} \mathrm{L}^{-1}\right)$ when compared with control cultures (1.42 and $1.39 \mathrm{mg} \mathrm{L}^{-1}$ respectively) (24). Our study was firstly using PHEL and TYR for elevating VBL and VCR in CHR. In addition, the VCR was increased 31-fold comparable with the control CHR. The CHR in our study required a significant primary growth stage before stepping to the secondary metabolite accumulation. PHEL may be applicable for both cultural phases as a supportive nutrition in the first stage and then become an effective precursor in the second stage.

\section{The effect of elicitor}

Fig. 4 and 5 Table 3 revealed only vinblastine was produced in CHR when using chitosan and methyl jasmonate elicitation.

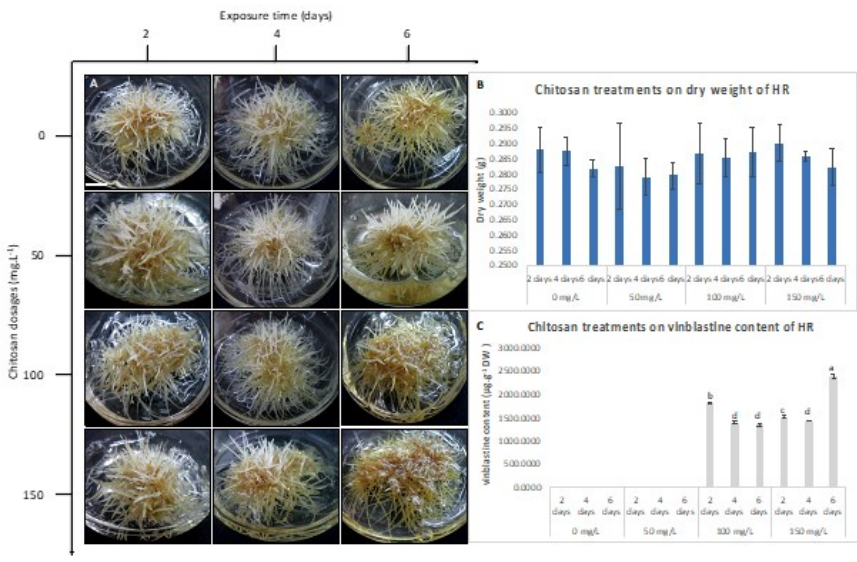

Fig. 4. Effect of the chitosan dosages and exposure time on CHR. (A) CHR phenotypes, (B) dry weight and (C) vinblastine contents. Error bars represent standard deviations. The value in line marked with different lower-case letters denote significant differences between samples at $p<0.05$ (Duncan's multiple range test). Scale bar $=1 \mathrm{~cm}$.

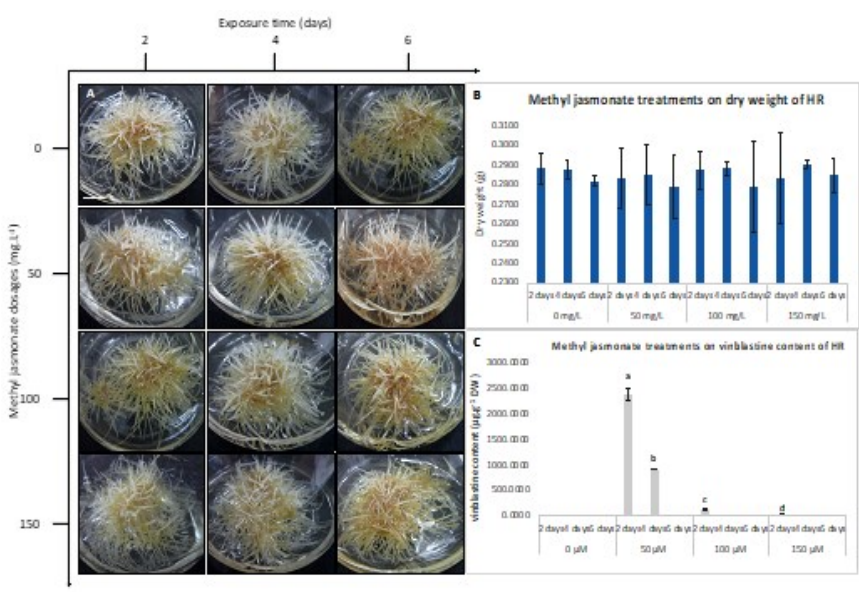

Fig. 5. Effect of the methy jasmonate dosages and exposure time on CHR. (A) CHR phenotypes, (B) dry weight and (C) vinblastine contents. Error bars represent standard deviations. The value in line marked with different lowercase letters denote significant differences between samples at $p<0.05$ (Duncan's multiple range test). Scale bar $=1 \mathrm{~cm}$ 
Table 3. Effect of chitosan and methyl jasmonate dosages and time exposure on CHR

\begin{tabular}{|c|c|c|c|c|c|c|c|}
\hline Chitosan dosages & Time exposure & $\mathrm{DW}(\mathrm{g})$ & VBL ( $\left.\mu \mathrm{g} \mathrm{g}^{-1} \mathrm{DW}\right)$ & Methyl jasmonate & Time exposure & DW (g) & VBL $\left(\mu g^{-1}\right.$ DW) \\
\hline & 2 days & 0.2879 & 0.0000 & & 2 days & 0.2879 & 0.0000 \\
\hline \multirow[t]{3}{*}{$0 \mathrm{mg} / \mathrm{L}$} & 4 days & 0.2877 & 0.0000 & $0 \mu \mathrm{M}$ & 4 days & 0.2877 & 0.0000 \\
\hline & 6 days & 0.2818 & 0.0000 & & 6 days & 0.2818 & 0.0000 \\
\hline & 2 days & 0.2825 & 0.0000 & & 2 days & 0.2830 & $2370.2790^{a}$ \\
\hline \multirow[t]{3}{*}{$50 \mathrm{mg} / \mathrm{L}$} & 4 days & 0.2792 & 0.0000 & $50 \mu \mathrm{M}$ & 4 days & 0.2847 & $911.4933^{b}$ \\
\hline & 6 days & 0.2796 & 0.0000 & & 6 days & 0.2788 & 0.0000 \\
\hline & 2 days & 0.2869 & $1833.5870^{\mathrm{b}}$ & & 2 days & 0.2871 & $125.9854^{c}$ \\
\hline \multirow[t]{3}{*}{$100 \mathrm{mg} / \mathrm{L}$} & 4 days & 0.2855 & $1400.7873^{d}$ & $100 \mu \mathrm{M}$ & 4 days & 0.2880 & 0.0000 \\
\hline & 6 days & 0.2872 & $1363.0420^{d}$ & & 6 days & 0.2789 & 0.0000 \\
\hline & 2 days & 0.2901 & $1526.5750^{c}$ & & 2 days & 0.2832 & $48.4800^{d}$ \\
\hline $150 \mathrm{mg} / \mathrm{L}$ & 4 days & 0.2859 & $1437.6680^{d}$ & $150 \mu \mathrm{M}$ & 4 days & 0.2903 & 0.0000 \\
\hline
\end{tabular}

The value marked with different lower-case letters denote significant differences between samples at $p<0.05$ (Duncan's multiple range test)

\section{Effects of chitosan}

As shown in Fig. 4, CTS dosages or time exposure did not reduce the growth of $\mathrm{CHR}$ comparable with the control $(p>$ 0.05). However, eliciting with CTS at high concentrations (100 and $150 \mathrm{mg} \mathrm{L}^{-1}$ ), the $\mathrm{CHR}$ revealed a significant increase of VBL content. In addition, increasing time exposure could help to enhance the production of VBL. After 6 days of elicitation, adding $150 \mathrm{mg} \mathrm{L}^{-1}$ CTS could reveal a remarkable result (2401.02 $\left.\mathrm{\mu g} \mathrm{g}^{-1} \mathrm{DW}\right)$. The color of $\mathrm{CHR}$ and medium turned into yellow only exposing with $150 \mathrm{mg} \mathrm{L}^{-1} \mathrm{CTS}$. The HPLC analysis of VCR accumulated in CHR cultured in 150 $\mathrm{mg} \mathrm{L}^{-1} \mathrm{CTS}$ after 6 days of elicitation was described in Fig. $6 C$.

\section{Effects of methyl jasmonate}

As shown in Fig. 5, MJ with any dosages or time exposure could not make detrimental effect on the growth ability of $\mathrm{CHR}$ in comparison with the control. The greatest content of VBL was produced in using $50 \mu \mathrm{M}$ and 2 days of MJ elicitation (2370.30 $\left.\mathrm{\mu g} \mathrm{g}^{-1} \mathrm{DW}\right)$. The HPLC analysis of VCR accumulated in $\mathrm{CHR}$ cultured in $50 \mu \mathrm{M} \mathrm{MJ}$ after 2 days of elicitation was revealed in Fig. 6D.

In the comparison between two elicitors, using methyl jasmonate with lower dosage as well as shorter exposure time of elicitation than chitosan, it could produce the same amount of vinblastine. Methyl jasmonate works as an exogenous signaling molecule; it increases the transcription of genes encoding enzymes involved in TIAs production (25). The methyl jasmonate effect in TIAs elevation was reported in many previous studies. In C. roseus, methyl jasmonate increased ajmalicine accumulation in cell suspension cultures (26), vindoline, catharanthine, and ajmalicine accumulation in meristem cell cultures in bioreactor systems (25), and ajmalicine and catharanthine accumulation in hairy root culture (27). Furthermore, it had a significant effect on the expression levels of TIAs biosynthesis genes in C.roseus prior blooming (28). In this study, methyl jasmonate promoted vinblastine accumulation $\left(2.370 \mu \mathrm{g} \mathrm{g}^{-1} \mathrm{DW}\right)$ in $\mathrm{CHR}$, whereas the control sample did not. However, vincristine was not discovered in these treatments.
A comparison between using precursor and elicitor on VBL and VCR production in the CHR

There were just a few reports working on VBL and VCR content of CHR. Determine the VCR was $442.3 \mathrm{ng} \mathrm{mg}^{-1} \mathrm{FW}$ but VBL was not detected. In comparison with our CHR, the VCR accumulated less content ( $\left.51.99 \mu \mathrm{g} \mathrm{g}^{-1} \mathrm{DW}\right)$ but significantly higher VBL content. It is noteworthy that VBL (which presented abundantly in our CHR) will transform into VCR during times of culture. After 7 weeks, CHR cultured in $1 \mu \mathrm{M}$ PHEL could produce both VBL and VCR with higher content than any others. This issue may indicate that CHR will be able for a remarkable VCR increase in further weeks of culture.

On the other hand, there was not any appearance of VCR when exposed to CTS or MJ. This issue could be elaborated by the transformation process from VBL to VCR. [1] The effect of elicitor (CTS or MJ) may release inhibited signals which inactivated of the enzyme transformed VBL to VCR and [2] VBL play a key role in responding to CTS or MJ and therefore VCR did not require. In this study, our CHR had sufficient ability to respond to the elicitor at the appropriate dosage, which led to an increase in VBL content, but not a reduction in growth by the time of elicitation. However, the less efficient in VCR production may due to a limitation in the experimental design of elicitor. It could be seen clearly in the use of $150 \mathrm{mg} \mathrm{L}^{-1}$ CTS with 6 days of elicitation which produced the highest of VBL content. Consequently, it is very likely that using a higher dosage or extending the time exposure will reveal a buildup of VCR content in our $\mathrm{CHR}$.

Therefore, it is clear that in culturing hairy roots of Catharanthus roseus, the use of both precursor and elicitor have an impact on increasing the accumulation of TIAS if we use it appropriately. Among them, using precursor (phenylalanine $1 \mu \mathrm{M}$ ) is the most clearly demonstrated.

\section{Conclusion}

Precursors or elicitors treatment enhanced the production of TIAs in our CHR clones. In particular, the use of elicitors required more time to find the appropriate induction condi- 
tions, while the use of precursors gave outstanding efficien- 6 cy in the treatment with $1 \mathrm{M}$ phenylalanine. The greatest yields of vincristine (51.99 $\left.\mathrm{mg} \mathrm{g}^{-1} \mathrm{DW}\right)$ and vinblastine (699.92 $\mu \mathrm{g} \mathrm{g}^{-1} \mathrm{DW}$ ) were obtained in the 7 th week (with biomass $0.306 \mathrm{~g} \mathrm{DW}$ ). This highlights the high potential in using precursors to produce vincristine from $\mathrm{CHR}$, especially $\mathrm{CHR}$ clones generated by Agrobacterium rhizogenes isolated in Vietnam.

\section{Acknowledgements}

This study was made possible by the Hi-Tech Agricultural Park Management Board in Ho Chi Minh City and the Plant 9 biotechnology laboratory, Department of Biotechnology \& Biotechnology, Faculty of Biology-Biotechnology, University of Sciences, Vietnam National University in Ho Chi Minh City (VNU-HCM).

\section{Authors contributions}

PTBV carried out the precursors and elicitors effect investigation and drafted the manuscript. DMC participated in the precursors and elicitors effect investigation and drafted the manuscript. ALB participated in the design of elicitors and precursors effect investigation and performed the statistical analysis. NNN carried out the CHR preparation and CHR resource. LVB and PNDQ conceived of the study, participated in manuscript editing, its design, and coordination. All authors read and approved the final manuscript.

\section{Compliance with ethical standards}

Conflict of interest: Authors do not have any conflict of interests to declare.

Ethical issues: None.

\section{References}

1. Gajalakshmi S, Vijayalakshmi S, Devi RV. Pharmacological activities of Catharanthus roseus: A perspective review [Internet]. Psu.edu. [cited 2021 Dec 1]. Available from: http:// citeseerx.ist.psu.edu/viewdoc/download? doi=10.1.1.302.1823\&rep=rep1\&type=pdf

2. Das S, Sharangi AB. Madagascar periwinkle (Catharanthus roseus L.): Diverse medicinal and therapeutic benefits to humankind. J Pharmacogn Phytochem. 2017;6(5):1695-701. Available from: https://www.phytojournal.com/archives/2017/vol6issue5/ PartY/6-5-182-590.pdf.

3. Aslam J, Khan SH, Siddiqui ZH, Fatima Z, Maqsood M, Bhat MA, Nasim SA, Ilah A, Ahmad IZ, Khan SA, Mujib A. Catharanthus roseus (L.) G. Don. An important drug: it's applications and production. Pharmacie Globale (IJCP). 2010;4(12):1-6.

4. Kabesh K, Senthilkumar P, Ragunathan R, Kumar RR. Phytochemical analysis of Catharanthus roseus plant extract and its antimicrobial activity. Int J Pure App Biosci. 2015;3(2):162-72. Available from: http://www.ijpab.com/form/2015\%20Volume\% 203,\%20issue\%202/IJPAB-2015-3-2-162-172.pdf

5. Alam MM, Naeem M, Khan MMA, Uddin M. Vincristine and vinblastine anticancer Catharanthus alkaloids: Pharmacological Applications and Strategies for Yield Improvement. In: Naeem M., Aftab T., Khan M. (eds) Catharanthus roseus. Springer, Cham. 2017. https://doi.org/10.1007/978-3-319-51620-2_11.
Van Der Heijden R, Jacobs DI, Snoeijer W, Hallard D, Verpoorte R. The Catharanthus alkaloids: pharmacognosy and biotechnology. Curr Med Chem. 2004;11(5):607-28. https:// doi.org/10.2174/0929867043455846

7. Sottomayor M, Barceló AR. The Vinca alkaloids: From biosynthesis and accumulation in plant cells, to uptake, activity and metabolism in animal cells. In: Studies in Natural Products Chemistry. Elsevier; 2006. p. 813-57. https://doi.org/10.1016/S1572-5995 (06)80041-4

8. Yu F, De Luca V. ATP-binding cassette transporter controls leaf surface secretion of anticancer drug components in Catharanthus roseus. Proc Natl Acad Sci U S A. 2013;110 (39):15830-5. https://doi.org/10.1073/pnas.1307504110

9. Parihar S, Dwivedi NK. Comprehensive analysis of liquid and semisolid culture system for in vitro propagation and conservation of Caralluma edulis: an appetite suppressant medicinal succulent of the indian thar desert. Plant Cell Biotechnol Mol Biol. 2019 Nov 23:1020-31. Available from: https://www.ikppress.org/ index.php/PCBMB/article/view/4799

10. Shanks JV, Morgan J. Plant "hairy root" culture. Curr Opin Biotechnol. 1999;10(2):151-15. https://doi.org/10.1016/S0958-1669 (99)80026-3

11. Wang JW, Wu JY. Effective elicitors and process strategies for enhancement of secondary metabolite production in hairy root cultures. Adv Biochem Eng Biotechnol. 2013;134:55-89. https:// doi.org/10.1007/10_2013_183

12. Ruiz-May E, Galaz-Avalos RM, Loyola-Vargas VM. Differential secretion and accumulation of terpene indole alkaloids in hairy roots of Catharanthus roseus treated with methyl jasmonate. Mol Biotechnol. 2009;41(3):278-85. https://doi.org/10.1007/s12033008-9111-2

13. Zhou M-L, Zhu X-M, Shao J-R, Wu Y-M, Tang Y-X. Transcriptional response of the catharanthine biosynthesis pathway to methyl jasmonate/nitric oxide elicitation in Catharanthus roseus hairy root culture. Appl Microbiol Biotechnol. 2010;88(3):737-50. https://doi.org/10.1007/s00253-010-2822-x

14. Rijhwani SK, Shanks JV. Effect of elicitor dosage and exposure time on biosynthesis of indole alkaloids by Catharanthus roseus hairy root cultures. Biotechnol Prog. 1998;14(3):442-49. https:// doi.org/10.1021/bp980029v

15. Nguyen NN, Van Bui L. Isolation and identification of Agrobacterium rhizogenes inducing hairy roots of Catharanthus roseus in vivo. Sci Technol Dev J - Nat Sci. 2017;1(T1):48-59. https:// doi.org/10.32508/stdjns.v1iT1.434

16. Nguyen NN, Le BV. Hairy root induction in Catharanthus roseus by various strains of Agrobacterium rhizogenes isolated in Vietnam. Science and Technology Development Journal. 2016 Jun 30;19(2):44-52. https://doi.org/10.32508/stdj.v19i2.788

17. Gamborg OL, Miller RA, Ojima K. Nutrient requirements of suspension cultures of soybean root cells. Exp Cell Res. 1968;50 (1):151-58. https://doi.org/10.1016/0014-4827(68)90403-5

18. Zhou H, Tai Y, Sun C, Pan Y. Rapid identification of vinca alkaloids by direct-injection electrospray ionisation tandem mass spectrometry and confirmation by high-performance liquid chromatography-mass spectrometry. Phytochem Anal. 2005;16(5):32833. https://doi.org/10.1002/pca.852

19. Alam P, Sharaf-Eldin MA. Limited production of plant derived anticancer drugs vinblastine and vincristine. Planta Med [Internet]. 2016;82(05). https://doi.org/10.1055/s-0036-1578706

20. Cao DM, Vu PTB, Hoang MTT, Bui AL, Quach PND. Developing a sufficient protocol for the enhancement of $a$-glucosidase inhibitory activity by Urena lobata L. aeroponic hairy roots using exogenous factors, a precursor and an elicitor. Plants. 2020;9(4):548. https://doi.org/10.3390/plants9040548

21. Shinde AN, Malpathak N, Fulzele DP. Enhanced production of 
phytoestrogenic isoflavones from hairy root cultures of Psoralea corylifolia L. Using elicitation and precursor feeding. Biotechnol Bioprocess Eng. 2009;14(3):288-94. https://doi.org/10.1007/ s12257-008-0238-6

22. Kutchan TM. Alkaloid biosynthesis - The basis for metabolic engineering of medicinal plants. Plant Cell. 1995;7(7):1059-70. https://doi.org/10.1105/tpc.7.7.1059

23. Peebles CAM, Hong S-B, Gibson SI, Shanks JV, San K-Y. Effects of terpenoid precursor feeding on Catharanthus roseus hairy roots over-expressing the alpha or the alpha and beta subunits of anthranilate synthase. Biotechnol Bioeng. 2006;93(3):534-40. https://doi.org/10.1002/bit.20739

24. Gaviraj EN, Veeresham C. Effect of precursors and organic compounds on alkaloid production in transformed root cultures of Catharanthus roseus. var. nirmal. Pharm Biol. 2006;44(5):371-7. https://doi.org/10.1080/13880200600748929

25. Zhou P, Yang J, Zhu J, He S, Zhang W, Yu R, Zi J, Song L, Huang X. Effects of $\beta$-cyclodextrin and methyl jasmonate on the production of vindoline, catharanthine and ajmalicine in Catharanthus roseus cambial meristematic cell cultures. Appl Microbiol Biotechnol. 2015;99(17):7035-45. https://doi.org/10.1007/s00253015-6651-9
26. Almagro L, López Perez AJ, Pedreño MA. New method to enhance ajmalicine production in Catharanthus roseus cell cultures based on the use of cyclodextrins. Biotechnol Lett. 2011;33(2):381-85. https://doi.org/10.1007/s10529-010-0430-6

27. Vázquez-Flota F, Moreno-Valenzuela O, Miranda-Ham ML, CoelloCoello J, Loyola-Vargas VM. Catharanthine and ajmalicine synthesis in Catharanthus roseus hairy root cultures: Medium optimization and elicitation. In: Primary and Secondary Metabolism of Plants and Cell Cultures III. Dordrecht: Springer Netherlands; 1994. p. 273-79. https://doi.org/10.1007/978-94-011-0237-7_23

28. Pan Q, Saiman MZ, Verpoorte R, Tang K. Accumulation of terpenoid indole alkaloids in jasmonic acid elicited Catharanthus roseus plants before and during flowering. Pak J Bot. 2018;50 (3):1077-83. Available from: http://www.pakbs.org/pjbot/ papers/1521355666.pdf

29. Hanafy MS, Matter MA, Asker MS, Rady MR. Production of indole alkaloids in hairy root cultures of Catharanthus roseus L. and their antimicrobial activity. S Afr J Bot. 2016;105:9-18. https:// doi.org/10.1016/j.sajb.2016.01.004 